\title{
Sexualidade na adolescência: análise da influência de fatores culturais presentes no contexto familiar
}

\author{
The influence of family cultural beliefs on adolescent's sexual behavior
}

\author{
Sexualidad en la adolescencia: análisis del influjo de factores culturales presentes en el contexto \\ familiar
}

\section{Leilane Barbosa de Sousa1, Janaína Franscisca Pinto Fernandes $^{2}$, Maria Grasiela Teixeira Barroso ${ }^{3}$}

\section{RESUMO}

Objetivo: Compreender a complexidade da influência de elementos culturais, presentes no contexto familiar, sobre o comportamento sexual do adolescente. Métodos: Este trabalho foi produzido a partir de um estudo de caso realizado com a família de uma adolescente, fundamentado nos preceitos da teoria do cuidado transcultural. Resultados: Verificamos concepções errôneas e escrúpulos sem fundamentos sobre sexualidade, presentes no contexto familiar, que exerceram significativa influência no comportamento da adolescente. Entre eles a crença de que conversar sobre sexo pode induzir a filha a iniciar a prática sexual. Considerações finais: Percebemos a importância da realização de atividades de educação sexual direcionadas para o esclarecimento de conceitos que possam prejudicar a saúde e a qualidade de vida de adolescentes.

Descritores: Adolescente; Família; Sexualidade; Comportamento sexual; Cultura

\begin{abstract}
Objective: To understand the complexity of the influence of family cultural beliefs on adolescent's sexual behavior. Method: The transcultural care theory guided this case study of family members of a female adolescent. Results: Family members' misconceptions and scruples about sexuality meaningfully influenced the adolescent's behavior. Family members believe that talking about sex with the adolescent could lead to earlier engagement in sexual activities. Final considerations: Providing sexual education for family members of adolescents may be an important strategy to clarify misconceptions, which in turn may change family members' beliefs and attitudes toward sexuality. This might be an important step to promote adolescents' health and quality of life.
\end{abstract}

Keywords: Adolescent; Family; Sexuality; Sexual behavior; Culture

\section{RESUMEN}

Objetivo: Comprender la complejidad de la influencia de elementos culturales, presentes en el contexto familiar, sobre el comportamiento sexual del adolescente. Métodos: Este trabajo fue producido a partir de un estudio de caso realizado con la familia de una adolescente, fundamentado en los preceptos de la teoría del cuidado transcultural. Resultados: Verificamos concepciones erróneas y escrúpulos sin fundamentos sobre sexualidad presentes en el contexto familiar que ejercieron influencia significativa en el comportamiento de la adolescente. Entre ellos la creencia de que conversar sobre sexo puede inducir a la hija a iniciar la práctica sexual. Consideraciones finales: Percibimos la importancia de la realización de actividades de educación sexual orientadas a aclarar conceptos que puedan perjudicar la salud y la calidad de vida de adolescentes.

Descriptores: Adolescente; Familia; Sexualidad; Conducta sexual; Cultura

\footnotetext{
* Trabalho resultante das atividades realizadas no projeto "Educação em saúde no contexto da promoção humana: uma investigação na prevenção de riscos em Doenças Transmissiveis (DT) e Sexualmente Transmissiveis (DST)”, da Universidade Federal do Ceará - UFC - Ceará (CE), Brasil.

1 Acadêmica de Enfermagem da Universidade Federal do Ceará - UFC - Fortaleza (CE), Brasil; Bolsista do CNPq.

2 Acadêmica de Enfermagem da Universidade Federal do Ceará - UFC - Fortaleza (CE), Brasil; Bolsista PIBIC/CNPq.

${ }^{3}$ Professora Doutora Emérita da Universidade Federal do Ceará - UFC - Fortaleza (CE); Docente Livre.
} 


\section{INTRODUÇÃO}

Além das transformações físicas, a adolescência é marcada pelas descobertas e pela busca da superação de obstáculos ${ }^{(1)}$. As novas experiências na adolescência podem desencadear sentimentos de medo e insegurança. Como sexo é algo desconhecido no universo do adolescente, este tende a iniciar cada vez mais precocemente a prática de relações sexuais, muitas vezes até mesmo por pressão do grupo social no qual se encontra engajado ${ }^{(2)}$.

Em nossa sociedade, o tema sexualidade ainda encontra-se cercado de mistério e tabus, o que, cremos, é indício de atraso, pois, dada a relevância do tema, deveria haver clara discussão entre adultos e adolescentes inexperientes ${ }^{(3)}$. Diante do silêncio em casa, o adolescente tende a procurar informações com outros adolescentes também imaturos, contribuindo, dessa maneira, para a prática do sexo de forma insegura ${ }^{(4)}$.

Dados revelam que, no mundo, uma em cada três adolescentes de 19 anos já é mãe ou está grávida do primeiro filho, somente $30 \%$ dos jovens usam métodos contraceptivos e, pelo menos, $1 / 3$ das 30 milhões de pessoas infectadas pelo HIV têm entre 19 e 24 anos ${ }^{(5)}$. Esses problemas poderiam ser evitados se o adolescente encontrasse no ambiente familiar liberdade para discutir sobre sexo e sexualidade.

Entretanto, além de a família não oferecer informações necessárias sobre o assunto aos adolescentes, acreditando que esta é uma tarefa da escola e/ou dos serviços de saúde, existe também a forte influência de elementos culturais sobre esse comportamento. Crenças, valores e costumes permeiam o contexto de vida das pessoas, e influenciam a forma como elas se comportam diante de situações de saúde/doença ${ }^{(6-7)}$. Esses fatores culturais são influenciados pela visão de mundo, linguagem, religião e pelos contextos social, político, educacional, econômico, tecnológico, etno-histórico e ambiental de cada cultura em particular ${ }^{(8)}$.

A sociedade brasileira confere uma grande importância à sexualidade em termos culturais ${ }^{(9)}$. A complexidade dessa conexão entre sexualidade e cultura requer estudos cada vez mais aprofundados, sobretudo em se tratando do adolescente, um grupo que se vem apresentando cada vez mais vulnerável a riscos relacionados à saúde reprodutiva e sexual.

A família, comportando o berço cultural do indivíduo, deverá ser levada em consideração na construção do cuidado, que, por sua vez, deverá enfocar as necessidades e expectativas do adolescente e de sua família ${ }^{(10)}$.

Com base no exposto, o presente estudo foi desenvolvido com o objetivo de compreender a complexidade da influência de elementos culturais presentes no contexto familiar, bem como o próprio comportamento sexual do adolescente, visando identificar crenças, mitos e tabus sobre sexualidade, além de fornecer subsídios para o desenvolvimento de condutas de educação em saúde junto ao adolescente e à sua família.

\section{MÉTODOS}

A pesquisa foi idealizada a partir de um estudo de caso fundamentado nos preceitos da teoria do cuidado transcultural $^{(8)}$,e realizada com a família de uma adolescente cadastrada no Centro de Desenvolvimento Familiar (CEDEFAM), selecionada dentre as participantes de uma oficina sobre gravidez na adolescência, realizada no mês de maio de 2004, após cumpridos os procedimentos éticos.

A família selecionada para o estudo distinguia-se das demais pelas intercorrências relacionadas ao diálogo deficiente entre pais e filhos adolescentes, principalmente quando se abordam temas relacionados à sexualidade. A adolescente foi a informante principal, sendo os outros participantes da família informantes complementares.

O estudo foi realizado durante os meses de novembro e dezembro de 2004 e janeiro de 2005, na própria residência da adolescente, localizada no bairro Planalto do Pici, nas proximidades do Campus do Pici da Universidade Federal do Ceará (UFC), na cidade de Fortaleza-CE. Neste campus, situa-se o CEDEFAM, instituição pública de saúde onde alunos de graduação de cursos da área da Saúde participam de atividades de ensino, pesquisa e extensão.

Utilizamos, para a coleta de dados, o processo de observação-participação-reflexão ou modelo $\mathrm{OPR}^{(8)}$, que obedece às seguintes fases: observação primária e escuta; observação primária com participação limitada; observação primária com observação contínua, quando houve a aplicação do roteiro de entrevista; e, finalmente, a reflexão primária e reconfirmação dos achados com os informantes.

Como estratégias para a coleta de dados, realizamos seis visitas domiciliares, utilizando como instrumentos o diário de campo e um roteiro de entrevista contendo as seguintes questões norteadoras: $\mathrm{O}$ que é sexualidade? $\mathrm{O}$ que é sexo? Como você descobriu sua sexualidade? Como você vivencia sua sexualidade? Você conversa com alguém sobre sexualidade?

O processo de análise de dados foi realizado em quatro fases: a coleta, descrição e documentação dos dados brutos; a identificação dos descritos e componentes; a análise contextual, e a síntese de idéias dos dados colhidos, agrupando-os em temas maiores ${ }^{(8)}$.

A pesquisa obedeceu às instruções presentes na Resolução $n^{\circ}$. 196, de 10 de outubro de 1996, do Conselho Nacional de Saúde, referente a estudos a serem realizados com seres humanos. Foi preservado o anonimato dos participantes, identificados por 
pseudônimos. $\mathrm{O}$ projeto da pesquisa foi aprovado pelo Comitê de Ética em Pesquisa da UFC.

\section{RESULTADOS}

\section{Caracterizando a adolescente e seu contexto familiar}

Ana, nossa informante principal, tem 16 anos de idade. Afirma que só teve um parceiro sexual, o pai de seu filho e atual companheiro, que namorou por três meses antes da gravidez. Cursava a oitava série do Ensino Fundamental quando engravidou; por conta disso, abandonou os estudos. Não trabalha. Nega sinais ou sintomas sugestivos de DST, apesar de nunca ter realizado exame ginecológico nem utilizar preservativo durante suas relações sexuais.

Mora com a mãe em uma residência com quatro cômodos pequenos (sala, quarto, banheiro e cozinha), sendo o chão de areia batida e as paredes de tijolo sem reboco. $\mathrm{Na}$ casa, há energia elétrica, mas não existe sistema de água e esgoto. $\mathrm{O}$ ambiente apresenta más condições de higiene, ventilação e iluminação.

A família é composta por 13 pessoas, conforme demonstrado no genograma (Apêndice). Os membros da família estão identificados por pseudônimos.

D. Maria, a mãe, teve sua primeira gravidez ainda na adolescência, quando tinha 13 anos de idade, assim como suas filhas Carla e Ana, que engravidaram pela primeira vez aos 17 e 16 anos, respectivamente.

\section{Descobrindo a Sexualidade}

A gravidez precoce e/ou indesejada de D. Maria parece ter sido assimilada, de alguma forma, pelas filhas, como algo não preocupante, o que reforça o pensamento de que normas e modos de vida são compartilhados, transmitidos e apreendidos por pessoas pertencentes a uma determinada cultura ${ }^{(8,11)}$.

Apesar de Carla e Ana encontrarem-se em faixas etárias aproximadas, não ocorreu diálogo sobre sexo, evidenciando que o tabu sobre sexualidade parece persistir na família, mesmo quando se trata do relacionamento entre irmãs adolescentes.

A primeira relação sexual, definida por Ana como a descoberta da sexualidade, aconteceu de forma imprudente, impulsionada pelo desejo do namorado e pelo medo que a menina teve de perdê-lo, conforme podemos observar:

Eu nem sabia direito das coisas... Também nem tinha muita vontade de fazer, mas ele queria... Ai aconteceu (...) Se eu não fizesse não ia faltar quem quisesse fazerer. E você sabe como é bomem... (Ana).

É possível detectar, no discurso da adolescente, o mito de que não há risco de engravidar na primeira relação sexual; isso pode tornar adolescentes suscetíveis a engravidar precocemente. Ana acredita que Na primeira vez. é difícil de engravidar..., por isso, não tomava pílula.

\section{Vivenciando a Sexualidade}

Após a primeira relação sexual, a adolescente passa a apresentar certa preocupação em relação à gravidez; entretanto, a escolha de um método contraceptivo parece ser baseada em crenças desenvolvidas a partir da observação de pessoas do próprio convívio familiar, demonstrando que a visão de mundo de um indivíduo é desenvolvida através da influência de diversos fatores presentes em seu contexto sócio-cultural ${ }^{(8)}$. Tomemos o depoimento abaixo:

Nunca vi minha mãe nem minha irmã tomando nada pra não engravidar, por isso não aprendi a tomar (...) Minha irmã engravidou por causa da camisinha que não prestava, era dessas que dão no posto... (Ana).

Para a adolescente, pareceu mais sensato acreditar no método desconhecido proposto pelo namorado (coito interrompido) do que no relato de uma experiência mal-sucedida em relação ao uso da camisinha, como podemos verificar pelo depoimento a seguir:

Das poucas vezes que a gente teve relação antes da gravidez dele [filho] também não usei nada. Meu namorado me disse que sabia como fazer pra eu não engravidar. Eu confiei nele. Ai deu no que deu, engravidei! (Ana).

Outro fator bastante atuante na procura por um método contraceptivo é o tabu sobre sexo, presente na família e na sociedade. As dimensões culturais e a estrutura social podem exercer influência em diferentes contextos ambientais. Podemos evidenciar essa realidade através do depoimento da adolescente:

Só agora que minha mãe já sabe que eu tenho relação, eu tomo pílula. Nunca fui ao posto antes da gravidez, com medo de alguém descobrir. (...) Não ia pedir pra minha mãe, né? Nem pra minha irmã, porque ela ia contar pra minha mãe (Ana).

Verificamos que os tabus sobre sexualidade refletemse mais marcantemente no ambiente familiar do adolescente do sexo feminino, dado que os pais tendem a ser mais rígidos com as garotas. As desigualdades de gênero condicionam os indivíduos a assumirem padrões de comportamento distintos; assim, o ser adolescente é culturalmente direcionado a pensar e agir de acordo com a natureza de seu sexo ${ }^{(12)}$. Ana confirma esse pensamento, afirmando que tem vergonha de dormir em sua própria casa com o namorado e que, por ele ser homem, lá ninguém 
fala nada... (Ana).

\section{Conversando sobre Sexualidade}

O diálogo entre pais e adolescentes no caso em estudo é muito restrito. Não há abertura para conversar sobre questões pessoais, íntimas. A dificuldade em procurar os pais para esclarecer dúvidas sobre assuntos relacionados à sexualidade está vinculada ao sentimento de medo de sofrer represálias. Tabus e preconceitos impedem o indivíduo, de até mesmo, buscar aprender. Diante disso, o adolescente busca auxílio com outros adolescentes, visando à troca de idéias ou mesmo ao compartilhamento de medos ${ }^{(13-14)}$.

Os pais, embasados na crença de que a conversa sobre sexo pode induzir a adolescente a praticá-lo, procuram preservar o silêncio sobre o assunto; contudo, a questão da saúde sexual deve ser abordada mesmo no início da adolescência ${ }^{(4,15)}$. Outra crença que percebemos, por parte da mãe, foi a de que a adolescente procuraria conversar sobre sexualidade quando desejasse iniciar a prática de relações sexuais, o que não aconteceu:

Ela [a filha Ana] nunca me procurou! Eu não conversava pra não incentivar... Se eu percebesse que tava acontecendo alguma coisa eu ia conversar com ela, mas ninguém imaginava que ela tava tendo relação (D. Maria).

A repressão à sexualidade humana é um fato milenar e interfere no comportamento das pessoas ${ }^{(15)}$. Acreditando que a filha adolescente não pratique relação sexual, os pais evitam discutir sobre sexo e ficam à espera de "algum sinal" que indique que a jovem descobriu a sexualidade. Entretanto, esse sinal pode surgir como produto de uma prática sexual desprovida de orientações ou baseada em informações inadequadas.

Somente após a percepção tardia de que a filha adolescente começou a praticar sexo, a mãe passa a conversar com ela sobre esse assunto. Ainda assim, a conversa se restringe apenas a orientações superficiais sobre prevenção da gravidez, de acordo com o que Ana afirma: Ela [mãe] me dá conselho para eu não engravidar.

As DST constituem algo distante para a realidade da mãe, a qual acredita no mito de que somente pessoas que vivem de forma promíscua, ou indivíduos que se relacionam com essas pessoas, estão propensos a adquirir DST. A crença, por parte da mãe, de que a camisinha não é eficiente como método contraceptivo, também contribui para a não adesão a este método por parte da adolescente, o que, por sua vez, expõe a jovem ao risco de contrair uma DST. Os conceitos atuais sobre sexualidade ainda guardam consigo a essência de gerações anteriores, carregada de mitos e crenças ${ }^{(15)}$.

Sempre tem história de gente que engravida com camisinha.
Com pílula, se tomar direito, nunca vi! (...) é mais fácil engravidar do que pegar doenças. A não ser que a pessoa fique com muitos homens ao mesmo tempo, ou fique com um homem que tem outra mulher! (D. Maria)

As experiências passadas de indivíduos explicam e interpretam os modos de vida humana em determinados contextos culturais, levando-nos a compreender condutas em determinadas situações; isto está relacionado ao conceito de etno-história ${ }^{(8)}$. Essa situação é inconscientemente reconhecida pela própria adolescente, ao afirmar que mesmo quando a família não se mete, influencia a sexualidade com os exemplos (Ana).

A família é uma instituição que articula a história social, política e econômica do lugar e da época nos quais se encontra ${ }^{(16)}$.

Ajustando e repadronizando o cuidado cultural

Procuramos negociar com a família o que deveria ser preservado, ajustado ou repadronizado em relação ao cuidado, tendo por princípio o respeito aos valores culturais do cliente ${ }^{(8)}$.

A primeira pauta em discussão foi a respeito da importância do diálogo entre pais e filhos. D. Maria reconheceu que esperar que o adolescente procure os pais para conversar sobre sexo e sexualidade não é a melhor estratégia de cuidado, salientando a importância de orientar para a prevenção, mesmo antes que o adolescente procure informações. Ela percebeu que $O$ negócio é prevenir mesmo, orientar... (D. Maria).

Carla, por sua vez, parece compreender a barreira entre pais e filhos e a dificuldade dos pais em tratar de assuntos referentes à sexualidade com seus filhos, reconhecendo que deve ser ruim pra eles [pais] também falar sobre essas coisas... (risos) (Carla).

Em contrapartida, o tabu sobre o tema sexualidade parece descender de raízes mais profundas. Ana concorda com a necessidade de mudar e/ou reajustar padrões de comportamento, mas ressalta que a mudança ocorre de forma gradativa, que ninguém consegue mudar de uma hora pra outra... (risos) (Ana).

$\mathrm{O}$ atendimento de enfermagem, baseado em cuidados e práticas aprendidos formal e cognitivamente, e obtidos através de instituições educacionais ${ }^{(8)}$, serviu como eixo para a repadronização do cuidado, antes baseado em mitos e crenças sem fundamento. Procuramos esclarecer questões sobre vulnerabilidade em adquirir DST e engravidar precocemente ou em um momento não desejado, assim como sobre os métodos para prevenir DST e gravidez, além de sua confiabilidade.

\section{CONSIDERAÇÕES FINAIS}

As crenças, os mitos e os tabus sobre sexualidade, 
identificados no contexto familiar desta adolescente, exerceram significativa influência em sua prática sexual. A vivência da sexualidade baseada em convicções errôneas, idéias falsas e escrúpulos sem fundamento positivo desencadearam conseqüências irreversíveis, como a gravidez precoce, e favoreceram condições de risco para a adolescente contrair DST. Isso, sem mencionar danos de ordem psicológica, não nitidamente referidos pela adolescente em estudo.

Os resultados desta pesquisa possibilitaram nossa reflexão a respeito da importância da realização de atividades de educação sexual, focalizando crenças, mitos e tabus, não só com adolescentes, mas, sobretudo, com seus pais, visto que os valores destes parecem exercer forte influência no comportamento de seus filhos.

É importante salientar, porém, que o cuidado, inclusive quando baseado em atividades de educação sexual, deve ser negociado entre os envolvidos, considerando seus valores e modos de vida.

\section{REFERÊNCIAS}

1. Fenwick E, Smith T. Adolescência - Guia de sobrevivência para pais e adolescentes. São Paulo: Ática; 1996.

2. Fernandes et al. Gravidez na Adolescência um Problema Social: visão de um grupo. In: Alves MDS, Pagliuca LMF, Barroso MGT, organizadores. Cultura e poder nas práticas de saúde: sociedade, grupo, família. Fortaleza: Pós Graduação/DENF/ Universidade Federal do Ceará; 1999.

3. Charbonneau PE. Adolescência e sexualidade. São Paulo: Paulinas; 1987.

4. Zagonel IPS. O ser adolescente gestante em transição: sob a ótica da enfermagem. Pelotas: Editora Universitária; 1999.

5. Rocha GLH. Adolescência e sexualidade [texto na Internet].[citado 2004 Set 24]. Disponível em: http:// br.geocities.com/glhr/cartilha/sex.html

6. Fernandes JFP, Sousa LB, Barroso MGT. Repercussão da gravidez no contexto sócio-familiar da adolescente - uma experiência. Acta Paul Enfermagem. 2004; 17(4): 400-6.

7. Budo MLD, Saupe R. Conhecimentos populares e educação em saúde na formação do enfermeiro. Rev Bras Enfermagem. 2004; 57(2):165-9.

8. Leininger MM, editor. Culture care diversity and universality: a theory of nursing. New York: National League for Nursing Press; c1991.

9. Barbosa RM, Aquino EML. Cultura sexual, ciência e política: uma entrevista com Richard Parker. Cad Saúde Pública. 2003; 19(Supl 2): 455-64.

10. Thiengo MA, Oliveira DC, Rodrigues BMRD. Representações sociais do HIV/Aids entre adolescentes: implicações para os cuidados de enfermagem. Rev Esc Enfermagem USP. 2005; 39(1): 68-76.

11. George JB, editor. Teorias de enfermagem: os fundamentos à prática profissional. 4a ed. Traduzido por Thorell AMV. Porto Alegre: Artmed; 2000. cap. 21. p. 297-308.

12. Luz AMH, Berni NIO. Feminino e Masculino: repercussões na saúde dos adolescentes. In: Ramos FRS, Monticelli M, Nitschke RG. organizadores. Projeto Acolher: Um encontro da enfermagem com o adolescente brasileiro. Brasília: Aben/ Governo Federal; 2000. p.37-45.

13. Patrício ZM. O cuidado com a qualidade de vida dos adolescentes: um movimento ético e estético de "Koans e Tricksters". In: Ramos FRS, Monticelli M, Nitschke RG, organizadores. Projeto Acolher: Um encontro da enfermagem com o adolescente brasileiro. Brasília: Aben/ Governo Federal; 2000. p. 121-43

14. Araújo TL. et al. Mães adolescentes: favorecimento da relação de ajuda. In: Alves MDS, Pagliuca LMF, Barroso MGT, organizadores. Cultura e poder nas práticas de saúde: sociedade, grupo, família. Fortaleza: Pós - Graduação/ DENF/ Universidade Federal do Ceará; 1999.

15. Jesus MCP. Educação sexual e Compreensão da Sexualidade na Perspectiva da Enfermagem. In: Ramos FRS, Monticelli M, Nitschke RG, organizadores. Projeto Acolher: Um encontro da enfermagem com o adolescente brasileiro. Brasília: Aben/Governo Federal; 2000. p. 46-55.

16. Botelho SMN, Ferriani MGC. Prostituição na adolescência: interfaces com a instituição familiar. Rev Bras Enfermagem. 2004; 57(2): 198-202. 


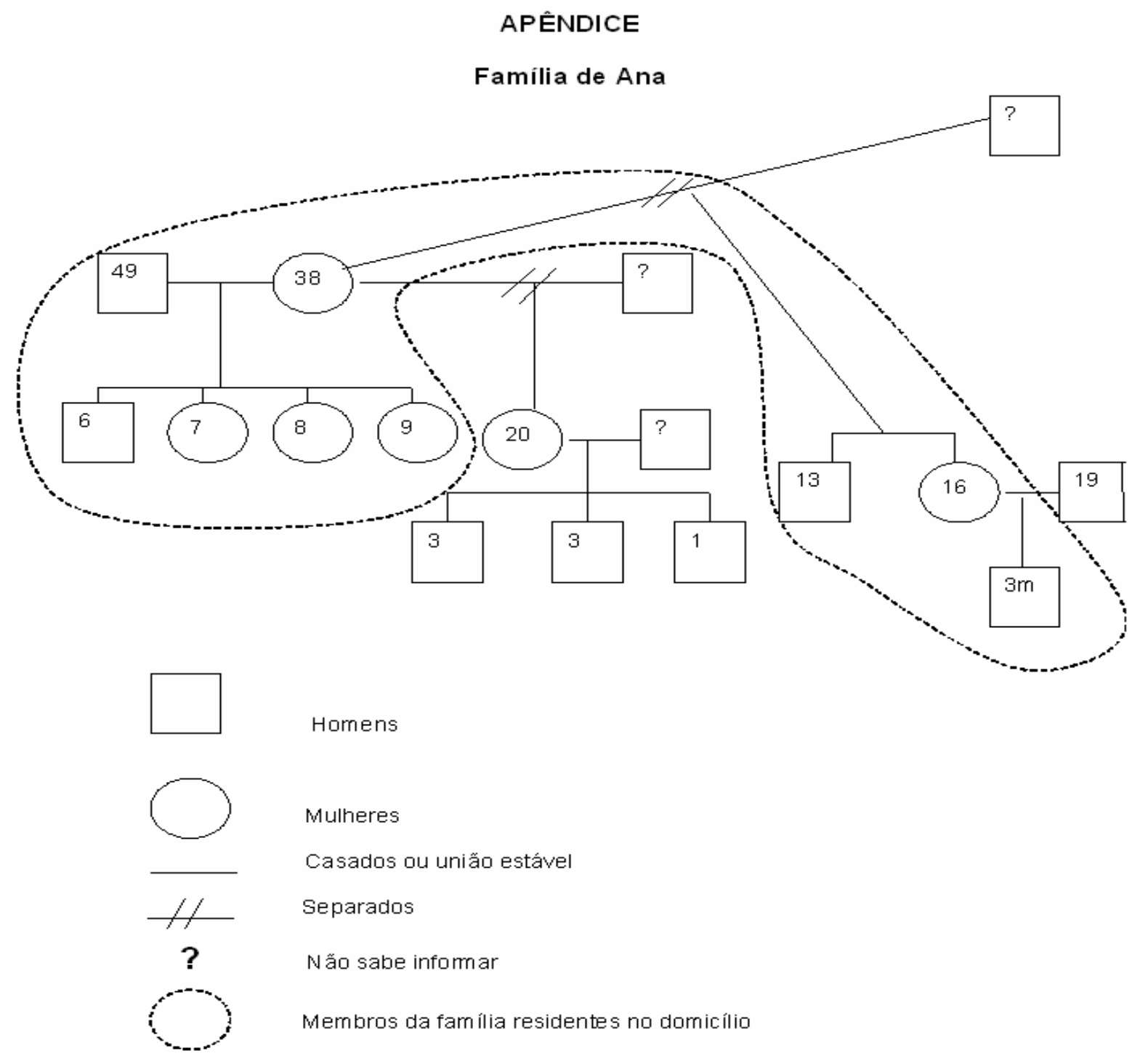

